\title{
Extração com líquidos pressurizados e fluidos supercríticos das sementes de guaraná: obtenção de compostos fenólicos
}

\author{
Vivian M. Amaral*, Ádina L. Santana, Gabriela A. Macedo, Julian Martínez.
}

\section{Resumo}

Sementes de guaraná foram extraidas pelas técnicas PLE (extração com líquidos pressurizados) e SFE (extração com fluido supercríticos), para obtenção de compostos fenólicos. A PLE recuperou fenólicos com mais eficiência que a SFE, por conta da natureza apolar do $\mathrm{CO} 2$, que dificultou a solubilização dos fenólicos polares. Para um mesmo processo uma quantidade maior de fenólicos foi extraída nas sementes de $25 \mu \mathrm{m}$ por conta da predisponibilidade de extrato na matriz sólida, que foi favorecida em menores tamanhos de partícula. O aumento da temperatura intensificou a extração de fenólicos no processo PLE por facilitar a transferência de massa dos fenólicos ao solvente.

Palavras-chave: Paullinia cupana, antioxidantes, fenólicos.

\section{Introdução}

A atuação de produtos à base de guaraná para melhora do desempenho cognitivo e aceleração do metabolismo se deve a sua composição em antioxidantes, tais como alcaloides e fenólicos. Atualmente as técnicas de extração devem ser eficientes, ambientalmente corretas e gerar extratos com alto rendimento em compostos bioativos. Neste trabalho, sementes brutas de guaraná com diâmetros de partícula de 25 e $125 \mu \mathrm{m}$ foram levadas a extração pelas técnicas PLE (extração com líquidos pressurizados) e SFE (extração com fluidos supercríticos), para avaliar o efeito desses processos na obtenção de compostos fenólicos (medidos pelo reagente de Folin-Ciocalteu) e capacidade antioxidante (medida pelo método FRAP). Etanol $50 \%$ foi usado como solvente na PLE e como co-solvente da SFE. Na SFE o solvente $\mathrm{CO}_{2}$ (pureza de 99\%) foi usado. Quatro níveis de temperatura $(40,50,60$ e $70 \stackrel{\circ}{\circ})$ ), foram usados, além da pressão de $10 \mathrm{MPa}$, vazão de solvente/cosolvente de $1 \mathrm{ml} / \mathrm{min}$ e vazão de $\mathrm{CO}_{2}$ a $6,36 \mathrm{~g} / \mathrm{min}$. O tempo de PLE e SFE foi de 60 minutos. As técnicas usadas foram comparadas à extração Soxhlet com etanol $100 \%$ por 6 horas.

\section{Resultados e Discussão}

As maiores temperaturas resultaram nos maiores rendimentos em extratos para as técnicas PLE $(22,43-$ $73,27 \mathrm{~g} / 100 \mathrm{~g}$ sementes) e SFE (49,58-60,30 $\mathrm{g} / 100 \mathrm{~g}$ sementes), a $70 \stackrel{\circ}{\circ}$ e $60{ }^{\circ} \mathrm{C}$, respectivamente. A PLE e a SFE mostraram-se mais eficientes que o método Soxhlet $(2,26-3,23 \mathrm{~g} / 100 \mathrm{~g})$.

O conteúdo de fenólicos (Figura 1) e a capacidade antioxidante (Figura 2) dos extratos foram maiores para a PLE das sementes de $25 \mu \mathrm{m}$. A mistura entre diferentes solventes (água, etanol e $\mathrm{CO}_{2}$ ) na SFE gerou uma grande diferença de polaridade, que diminuiu o rendimento da extração e simultaneamente atrapalhou a extração dos compostos fenólicos, que é também influenciada pela temperatura (diferentes pontos de ebuliçãoaumento/degradação de compostos disponíveis). Ao mesmo tempo, uma mistura de solventes com polaridades similares às dos fenólicos (como etanol e água, usada apenas na PLE) promove sinergia entre solubilidade $e$ dessorção dos compostos, promovendo maior extração de fenólicos em relação ao método Soxhlet $(60,07-78,68 \mathrm{mg}$ GAE/100g semente, 2,58-2,81 Trolox $/ \mathrm{mL}$ ), aplicado com etanol $100 \%$.

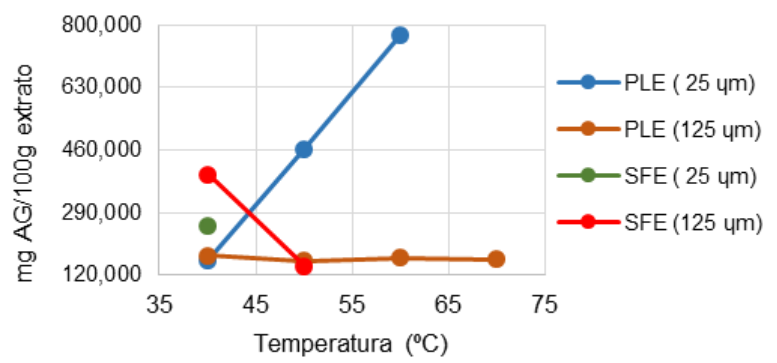

Figura 1. Análise de fenólicos totais para PLE e SFE (diâmetros de 25 e $125 \mu \mathrm{m}$ )

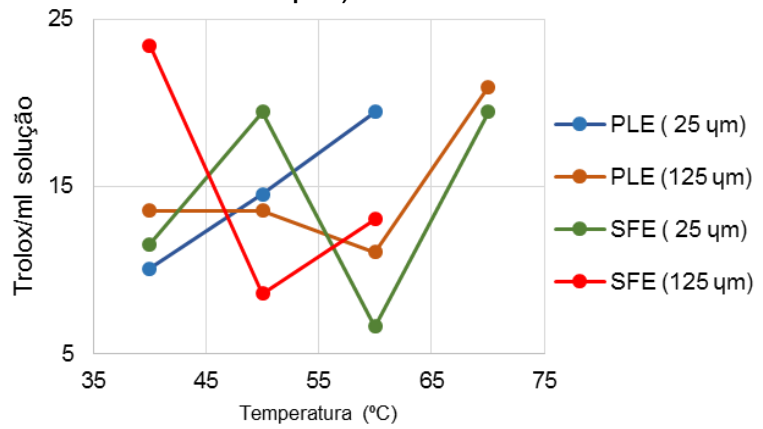

Figura 2. Análise de capacidade antioxidante (FRAP) para PLE e SFE (diâmetros de 25 e $125 \mu \mathrm{m}$ )

\section{Conclusões}

Apesar da menor eficiência da SFE para extrair fenólicos do guaraná em relação à PLE, ambas as técnicas mostraram-se efetivas em relação ao método convencional. Nas temperaturas mais altas foi possível atingir maior rendimento em extrato devido ao favorecimento da transferência de massa. As sementes de menor diâmetro de partícula foram associadas a maior teor de fenólicos totais e capacidade antioxidante por conta da predisponibilidade de extrato na matriz sólida.

\section{Agradecimentos}

Os autores agradecem ao PIBIC-CNPq pela bolsa de estudos e à FAPESP $(2017 / 23670-2)$ pela bolsa de pesquisa.

${ }^{1}$ Paes, J.; Dotta, R.; Martínez, J.; Extraction of phenolic compounds and anthocyanins using supercritical $\mathrm{CO} 2$ and pressurized liquids. Journal of Supercritical Fluids, 2014.

${ }^{2}$ Santana, Á. L., Osorio-Tobón, J. F., Cárdenas-Toro, F. P., Steel, C. J. \& Meireles, M. A. d. A. 2017. Partial-hydrothermal hydrolysis is an effective way to recover bioactives from turmeric wastes. Food Science and Technology, 0-0. 